\title{
Topiramate - Safety and Tolerability
}

\author{
M.W. Jones
}

\begin{abstract}
Topiramate is a new novel drug for the treatment of intractable seizures that is to be used in an adjunctive fashion. A review of the seven double-blind controlled studies was undertaken with special attention paid to safety and tolerability data. The studies were similar in design but used varying doses of the drug. To date there has been no evidence of serious systemic side effects such as rash, hepatotoxicity, cardiotoxicity, serious gastrointestinal toxicity or aplastic anemia. Renal stones were reported in $1.5 \%$ of patients with over $80 \%$ choosing to remain on the drug because of an improved quality of life. The unique observation of "abnormal thinking" was seen that seemed to be related to high doses and introducing the drug too rapidly. Patients, rather than describing psychomotor slowing, described a phenomenon of slow thoughts, decreased cognition, intermittent difficulty calculating, dulled thinking, blunted mental reactions. Lastly, weight loss appears in approximately $10-20 \%$ of patients and is probably related to dulling of appetite. Although increasing doses gave increasing degrees of seizure freedom, it appeared that doses beyond $600 \mathrm{mg} /$ day are often not well tolerated.
\end{abstract}

\begin{abstract}
RÉSUMÉ: Sécurité et tolérabilité du topiramate. Le topiramate est un nouveau médicament pour le traitement des crises résistantes au traitement. Il est utilisé comme adjuvant. Nous présentons une revue de sept études contrôlées en double insu en insistant sur les données sur la sécuritê et la tolérabilité de ce médicament. Ces études avaient un plan d'étude semblable mais utilisaient des doses différentes du médicament. À date, il n'y a pas d'évidence d'effets secondaires sérieux tels un rash, une hépatotoxicité, une cardiotoxicité, une toxicité gastro-intestinale sérieuse ou une anémie aplastique. Des calculs rénaux ont été rapportés chez $1.5 \%$ des patients et $80 \%$ des patients ont choisi de demeurer sous traitement parce que leur qualité de vie était améliorée. L'observation de "pensée anormale" semblait reliée à des doses élevées et à une augmentation trop rapide de la posologie. Les patients ont décrit un phénomène de bradyphrénie plutôt qu'un ralentissement psychomoteur, une diminution de la cognition, une difficulté intermittente à calculer, une pensée émoussée, des réactions mentales amorties. Finalement, une perte de poids est notée chez à peu près 10 à $20 \%$ des patients et est probablement reliée à une diminution de l'appétit. Bien que des doses croissantes aient entraîné une diminution des crises, il semble que des doses plus élevées que $600 \mathrm{mg} / \mathrm{jour}$ sont souvent mal tolérées.
\end{abstract}

Can. J. Neurol. Sci. 1998; 25: S13-S15

Anti-epileptic therapy is a long term proposition; it involves a minimum of 2 years duration for the majority of patients and a lifetime for others.' In selecting an appropriate anti-epileptic drug (AED), one wants to pick a medication that is both safe and tolerable. A number of studies ${ }^{2-7}$ have shown that topiramate is effective in a wide variety of seizure types and is thus a broad spectrum agent. The same studies which were similar in design also systematically looked at the drug for safety and tolerability. There are no currently available AEDs without adverse effects; as expected, since topiramate is primarily a central nervous system (CNS) drug working at the level of the neuron, the side effects are primarily neurological.

To date there has been no evidence of serious systemic side effects, such as rash, hepatotoxicity, cardio-toxicity, serious gastrointestinal toxicity, or aplastic anaemia. In an audit of 1200 patients, ${ }^{2}$ renal stones were reported in $1.5 \%$ of patients. However $83 \%$ ( 15 out of 18 ) of these patients chose to continue therapy with topiramate.

Properties of an Ideal Anti-epileptic Drug (AED) (no drug currently meets these requirements)

1) More potent, more effective than those currently available. 2) Broad spectrum of activity, long half life. 3) Specific mechanism of action, no tolerance. 4) Less toxicity, fewer side effects, no toxic metabolites. 5) Desired side effects i.e., benefit psychiatric symptoms. 6) Water soluble, low protein binding. 7) Drug levels available, no teratogenicity. 8) AFFORDABLE.

Topiramate achieves many of these goals but not each and every one of them.

\section{Results of Clinical Studies}

There were two large American studies ${ }^{3,4}$ using low dose 200 to $600 \mathrm{mg}$ per day, versus high dose 600 to $1,000 \mathrm{mg}$ per day. It was shown that those on higher doses in general did not achieve any better efficacy but did have more treatment emergent adverse effects. These two U.S. studies were similar in design in that the protocol dictated that each patient have rapid escalation where the dose was increased by $100 \mathrm{mg}$ per week until the patient achieved his randomized optimal dose $(200-1000 \mathrm{mg}$ per day). Similar double blind placebo add-on studies ${ }^{5-7}$ were done in Sweden, Great Britain and Italy using the fast escalation dose of $100 \mathrm{mg}$ per week. In total these 5 studies $^{8}$ showed that

From the Vancouver Hospital and Health Sciences Centre, University of British Columbia, Vancouver.

Reprint requests to: Michael W. Jones, Vancouver Hospital and Health Sciences Centre, Room 218 - 2775 Heather Street, Vancouver, British Columbia, Canada V5Z $1 \mathrm{M} 9$ 
about $5 \%$ of patients who were randomized to placebo withdrew because of treatment emergent adverse effects versus $14 \%$ who withdrew because of treatment emergent adverse effects from topiramate. It was also clearly shown that those who withdrew did so within the first two months of the rapid dose escalation and largely for CNS side effects, the most troublesome being "abnormal thinking".

It is noteworthy that in none of these studies nor any of the open label trials to date have any abnormalities been demonstrated in $\mathrm{CBC}$, liver, or renal parameters, and likewise EKGs and urinalysis have all been normal.

Shorvon ${ }^{8}$ analysed all patient exposures to date and reviewed the five controlled clinical trials. He then looked at the percentage of patients who were able to achieve their target dose. $98 \%$ of those on $200 \mathrm{mg}$ a day were successful as compared to $86 \%$ on $400 \mathrm{mg}$ per day, $69 \%$ on $600 \mathrm{mg}$ per day, $60 \%$ on $800 \mathrm{mg}$ a day, and $55 \%$ on $1,000 \mathrm{mg}$ a day. In other words, almost half the patients were unable to tolerate doses above $600 \mathrm{mg}$ per day.

It has also been clearly shown from these studies that the side effects can be both intrinsically drug related as well as dose related. Side effects that were felt to be related to the dose of the drug were confusion, anorexia and abnormal thinking. This is to be contrasted to side effects that were related to being on the drug but did not seem to be dependent on the dose. These included dizziness, ataxia, diplopia, paraesthesia and fatigue. These were generally rated mild to moderate and attenuated with time.

\section{CNS Side Effects (Table)}

These include dizziness, ataxia, paraesthesia, nervousness and fatigue. The most troublesome one is "thinking abnormal". From the Table this included the descriptors of language problems, psychomotor slowing, nervousness, difficulty with memory, confusion and difficulty with concentration. "Thinking abnormal" was found in $25-33 \%$ of patients in the double blind placebo studies. "Thinking abnormal" encompasses both slowed

Table: CNS related adverse effects.

Incidence of treatment emergent adverse effects in placebo vs.

Topiramate in add-on trials:

\begin{tabular}{lccc}
\hline & Placebo & $\begin{array}{c}\text { 200-400 } \\
\text { mg per day }\end{array}$ & $\begin{array}{c}\text { 600-1000 } \\
\text { mg per day }\end{array}$ \\
\hline Dizziness & $15.3 \%$ & $28.3 \%$ & $32.1 \%$ \\
Ataxia & 6.9 & 21.2 & 14.5 \\
Speech Disorders & 2.3 & 16.8 & 11.4 \\
Nystagmus & 9.3 & 15.0 & 11.1 \\
Paraesthesia & 4.6 & 15.0 & 19.1 \\
Tremor & 6.0 & 10.6 & 8.9 \\
Language problems & 0.5 & 6.2 & 10.4 \\
Coordination abnormal & 1.9 & 5.3 & 3.6 \\
Abnormal gait & 1.4 & 1.8 & 2.2 \\
Somnolence & 9.7 & 30.1 & 27.8 \\
Psychomotor slowing & 2.3 & 16.8 & 20.8 \\
Nervousness & 7.4 & 15.9 & 19.3 \\
Difficult with memory & 3.2 & 12.4 & 14.5 \\
Confusion & 4.2 & 9.7 & 13.8 \\
Depression & 5.6 & 8.0 & 13.0 \\
Difficulty with & 1.4 & 8.0 & 14.5 \\
concentration & & & \\
\hline
\end{tabular}

thoughts and a number of related phenomena such as decreased cognition, intermittent difficulty calculating, dulled thinking, blunted mental reactions, and slow responses. It does not include the separate categories of confusion or psychosis which would include hallucinations. Often the patient appears somewhat slower or his relatives say he is not doing as well at school or at work; he is just not processing his thoughts properly.

One of the author's patients' described how she had to think about each individual component step of how to do finger-nose testing. Something like that should have been automatic, but she had to process cognitively how to do it. Another of the author's patients who is a janitor described having difficulties in calculating how many rolls of toilet paper he needed to get out each day for all the toilets in the school where he worked. This type of mental calculation which he had been doing for years became difficult. In both of these instances, the symptoms totally reversed with a reduction in the medication, as shown in the above studies..$^{3-7,9}$ They seem to occur in high doses and seemed to be a function of increasing the dose too rapidly. This has led to the recommendation that topiramate not be increased any faster than $50 \mathrm{mg}$ per week.

\section{Weight Loss}

In contrast to other anti-seizure medications, this drug causes weight loss in $10-20 \%$ of patients. It is usually in the order of 1 $6 \mathrm{~kg}$ and seems to be most noticeable in those patients who were more overweight to begin with. Most of the weight loss occurs in the first 3 months but can go on up to 18 months. The mechanism of action is not known but is probably in some way related to the anorexia that is seen in $5-10 \%$ of patients. It is an interesting side effect when one considers that topiramate is derived from the naturally occurring sugar, monosaccharide D-fructose.

\section{Renal Stone Formation}

Although the anti-seizure activity of topiramate is not believed to be related in its ability to inhibit certain isoenzymes of carbonic anhydrase, this is likely the cause of the nephrolithiasis and the paraesthesia. To date $1.5 \%$ of patients have had renal stones. They are calcium phosphate stones, probably due to decreased citrate excretion. The incidence is similar to that seen in patients taking acetazolamide, which is about 10 times greater than expected in a similar untreated population. These stones occur predominantly in males, over $75 \%$ of them have passed spontaneously, $80 \%$ of the patients have opted to stay on topiramate because of a much improved quality of life. To date there does not appear to be any identified relationship between the dose and duration of therapy and the development of kidney stones.

\section{Therapy Limiting Adverse Effects}

To date all treatment emergent side effects have been identified within the first 12 months. There has been no increase in the severity of previously reported adverse effects nor emergence of new ones beyond that time. There have been no reports of delayed psychosis or depression.

\section{SUMMARY}

Topiramate appears to be effective and well tolerated in patients with refractory epilepsy. There are however some cautionary caveats to stress:

1) Development of tolerance and long term side effects may 
not be known. 2) Total number of patients included in trials is small and rare toxicities may have been missed. 3) New antiepileptic drugs preclude pregnant patients or those with no contraception and thus a large segment of the population has not been studied. 4) Anti-epileptic drug trials involve severe cases (multiple drugs and seizure types) and the results may be different in milder forms of epilepsy. 5) Post marketing surveillance will be necessary to detect any rare adverse effects.

\section{Conclusion}

It would appear that this agent has robust efficacy, is well tolerated and is a welcome addition for those patients previously proven to have therapy resistance epilepsy. Doses over 600 $\mathrm{mg} /$ day are not as well tolerated.

\section{REFERENCES:}

1. Shorvon SD. The epidemiology and treatment of chronic and refractory epilepsy. Epilepsia 1996; 37 (Suppl. 2): S1-S3.
2. Reife R, Pledger G, Lim P. Topiramate: Pooled analysis of six placebo-controlled trial. Epilepsia 1996; 37 (Suppl. 4): S74.

3. Faught E, Wilder BJ, Ramsay RE. Topiramate placebo-controlled dose-ranging trial in refractory partial epilepsy using 200-, 400-, and 600-mg daily dosages. Neurology 1996; 46: 1684-1690.

4. Privitera M, Fincham R, Penry J. Topiramate placebo-controlled dose-ranging trial refractory partial epilepsy using 600-, 800-, and 1000-mg daily dose. Neurology 1996; 46:1678-1683.

5. Ben-Menachem E, Henriksen O, Dam N. Double-blind, placebocontrolled trial of topiramate as add-on therapy in patients with refractory partial seizures. Epilepsia 1996; 37(6): 539-543.

6. Sharief M, Viteri C, Ben-Menachem E. Double-blind, placebo-controlled study of topiramate in patients with refractory partial epilepsy. Epilepsy Res 1996; 25: 217-224.

7. Tassinari CA, Michelucci R, Chauvel P. Double-blind, placebocontrolled trial of topiramate (600 mg per day) for treatment of refractory partial epilepsy. Epilepsia 1996; 37(8): 763-768.

8. Shorvon SD. Safety of topiramate: adverse events and relationships to dosing. Epilepsia 1996; 37 (Suppl. 2): S18-S22.

9. Rosenfeld W. Placebo-controlled trial of topiramate as adjunctive therapy to carbamazepine of phenytoin for partial onset epilepsy. Epilepsia 1996; 37 (Suppl. 5): S153. 